\title{
Desmatamento no sul do Estado de Roraima: padrões de distribuição em função de Projetos de Assentamento do INCRA e da distância das principais rodovias (BR-174 e BR-210)
}

\author{
Paulo Eduardo BARNI ${ }^{1}$, Philip Martin FEARNSIDE ${ }^{2}$, Paulo Maurício L. de A. GRAÇA ${ }^{3}$ \\ RESUMO \\ O desmatamento na Amazônia representa, atualmente, um dos principais problemas ambientais do Brasil. A contenção deste \\ processo requer políticas públicas baseadas no entendimento das forças que controlam, aceleram e desaceleram a perda de \\ floresta. Para avaliar ocorrências de desmatamento no sul do Estado de Roraima foram utilizados dois buffers de $20 \mathrm{~km}$ de \\ largura subdivididos em oito faixas de 2500 metros ao longo das duas principais rodovias da região: BR-174 e BR-210 em um \\ ambiente de Sistema de Informaçôes Geográficas - SIG. O período analisado foi entre 2001 e 2007, sendo utilizados dados \\ de desmatamento do PRODES e análises visuais em imagens TM Landsat 5. Também foram utilizados arquivos shapefile \\ da malha viária e de Projetos de Assentamento (PAs) do Sul do Estado de Roraima, junto com observaçóes de campo. Os \\ resultados mostraram que os desmatamentos do período estão fortemente relacionados com a disponibilidade de estradas e \\ com o número de famílias dentro dos PAs. O desmatamento foi maior na área da BR-210 pela presença na região de grandes \\ proprietários e invasóes de terras. O pólo madeireiro, situado à margem da BR-174, pode ter influenciado na formação de \\ pequenas áreas de desmatamento na região de Rorainópolis. A exploraçáo madeireira predatória e novas ocupaçóes de terras \\ estão acontecendo de forma rápida e desordenada. Este quadro indica forte potencial para a perda de floresta em Roraima \\ caso o fluxo de migraçáo para esta área aumentar, como seria esperado se Roraima for conectada ao "Arco do Desmatamento" \\ pela reabertura da Rodovia BR-319, ligando Manaus a Porto Velho.
}

PALAVRAS CHAVES: Amazônia, Exploração Madeireira, Ocupação Ilegal de Terras, Sistema de Informaçáo Geográfica.

\section{Deforestation in the southern portion of the Roraima State: distribution with respect to INCRA settlement projects and distance from major highways (BR-174 and BR-210)}

\begin{abstract}
Deforestation in the Amazon currently represents one of the greatest environmental issues in Brazil, and stopping this process requires public policies based on understanding the forces that control the forest loss in different parts of Amazonia. We evaluated deforestation in the southern portion of Roraima State using a Geographical Information System (GIS) to delineate buffers along each of the two main highways that cross the region: BR-174 and BR-210. Each buffer was $20 \mathrm{~km}$ wide and was divided into eight strips $2500 \mathrm{~m}$ in width. The study covered the 2001-2007 period using annual deforestation data from PRODES vector files and visual analysis of TM Landsat 5 imagery. We also used shape files of roads and settlement projects in the southern part of Roraima coupled with field observations. Deforestation in the period was strongly related to the availability of roads and to the number of families present in the settlement project. The occurrence of deforestation was highest in the area of the BR-210 where large landowners and land invasions were present. The logging center on the BR-174 may have influenced the formation of small clearings in the Rorainópolis city neighbor. Predatory logging and new land occupations by both small and large landholders are spreading quickly in a disorderly fashion. This situation has high potential for forest loss since migration is expected to increase if Roraima is connected to the "Arc of Deforestation" by reopening the BR-319 Highway, which would connect Manaus to Porto Velho.
\end{abstract}

KEY WORDS: Amazon, Logging, Illegal Occupation of Lands, Geographic Information System.

1 Instituto Nacional de Pesquisas da Amazônia-INPA, Av. André Araújo, 2936, Aleixo, CEP 69060-001, Manaus - AM. E-mail: pbarni@inpa.gov.br

2 Instituto Nacional de Pesquisas da Amazônia-INPA, Manaus - AM. E-mail: pmfearn@inpa.gov.br

${ }^{3}$ Instituto Nacional de Pesquisas da Amazônia-INPA, Manaus - AM. E-mail: pmlag@inpa.gov.br 


\section{INTRODUÇÃO}

O desmatamento na Amazônia representa, atualmente, um dos principais problemas ambientais no Brasil, e a contenção do avanço deste processo requer políticas públicas baseadas no entendimento das forças que controlam, aceleram e desaceleram a perda de floresta em diferentes partes da regiáo amazônica (Fearnside 2003; 2008). Aumentos na a taxa de migração, implantação de Projetos de Assentamento (PAs) e proximidade de rodovias são fatores chaves em acelerar o desmatamento, enquanto que a criaçáo de Unidades de Conservação (UCs) é importante em freá-lo (Nepstad et al. 2006). Estes fatores são importantes na previsão da velocidade e da localização de desmatamento sob diferentes cenários de infra-estruturas e de políticas futuras, que é uma prioridade no Estado de Roraima. A parte sul deste estado, além de ser uma das frentes mais ativas de desmatamento hoje, é previsto a receber fluxos migratórios muito maiores se for concretizada a proposta para a reconstrução da rodovia BR-319 (ManausPorto Velho), fornecendo uma conexão direta com o "Arco de Desmatamento".

De acordo com o Instituto Nacional de Colonizaçáo e Reforma Agrária - INCRA (2007) existem 48 PAs atualmente no interior do Estado de Roraima situados ao longo das principais estradas e rodovias que cortam o Estado. Deste total, 22 (45,8\%) pertencem aos municípios do Sul de Roraima, abrigando, por sua vez, $1.802 \mathrm{~km}$ de estradas da malha viária da região $(57,1 \%)$ e 8.173 famílias assentadas até 2007 (Brasil, INCRA 2007). No período de 1955 a 1981, as regiôes sul e sudeste do Estado de Roraima pertenciam unicamente ao município de Caracaraí (Mourão 2003). Daí então, os atuais municípios do sul de Roraima foram sendo formados a partir da criação de PAs naquele município (Barbosa 1990). Esse processo pode ser visto ainda hoje ao longo da BR-174 e BR210 no sul do Estado.

A partir dos anos 1990 as taxas anuais de crescimento demográfico decaíram drasticamente, passando de $9,6 \%$ no período de 1980-1991 para 2,8\% entre 1991-1996 causado pelo fechamento do garimpo (Mourão 2003). As taxas de crescimento voltaram a subir a partir de 1995/1996, resultado de estratégia política do governo estadual em reordenar e dinamizar os assentamentos na regiáo, promovendo melhorias na infra-estrutura e criação de novos PAs para atração de migrantes para a regiāo (Mourão 2003). O asfaltamento da BR-174 e parte da BR-210 entre 1995-1997 facilitaram esse processo.

\section{A questão fundiária em Roraima}

Além dos fatores comuns vistos em outros estados da região amazônica, no que diz respeito à regularização da posse e ocupação da terra (Oliveira 2005; Loureiro e Pinto 2005; Barreto et al. 2008a), em Roraima a questáo esbarrava na Legislaçáo Federal que proibia a transferência de terras da Uniáo para os estados. Isso porque o governo federal ainda náo havia repassado as terras da União arrecadadas ao Estado de Roraima pelo INCRA, quando este passou de Território Federal para um Estado da federação em 1989. A falta de ordenamento e deficiência na política de assentamentos, além de dificultar o desenvolvimento estadual, levou a invasôes de terras e sua concentração, abandono e venda com conseqüente degradação ambiental (Mourão 2003).

\section{Aspectos sócio-econômicos do Sul do Estado de Roraima}

Mourão (2003) associou padróes de degradação do ambiente no sudeste do Estado com a origem dos colonos e aos programas de colonização movidos por interesses políticos. Segundo a autora, a degradaçáo se daria pelo desmatamento inicial para o plantio de lavouras anuais e de bananas. No final do ciclo de produçáo de banana haveria o semeio de capim para criaçáo de pastagens.

A atividade madeireira no sul de Roraima acompanha a dinâmica do "boom e colapso", característico das fronteiras de colonização da Amazônia brasileira (Barbosa 1990; Barbosa et al. 2008; Rodrigues et al. 2009). Os maiores fornecedores de madeira seriam os projetos de assentamento (Mourão 2003; Albuquerque et al. 2004; Barbosa et al. 2008) e áreas demarcadas ilegalmente.

Como visto acima, os processos e padróes de desmatamento em Roraima e mais precisamente no Sul do Estado, estariam fortemente ligados à abertura de PAs, invasóes de terras públicas e exploração madeireira desordenada (Holmes et al. 2002; Asner et al. 2006), com consequente agravamento das questôes fundiárias. Neste contexto, os PAs e as áreas de invasōes forneceriam a madeira para alimentar a indústria madeireira, assim financiando a derrubada da floresta nos lotes. A indústria retribuiria com a construção de uma rede de estradas que possibilitasse o escoamento da produção agrícola e servisse de acesso aos pequenos agricultores assentados nos PAs e nas posses demarcadas irregularmente.

Diante do exposto, esse trabalho teve como objetivos: a) analisar as ocorrências de desmatamento anual e sua distribuiçáo espacial em funçáo dos projetos de assentamento e da distância das duas principais rodovias (BR-174 e BR-210) que cortam o sul do Estado de Roraima, entre os anos de 2001 a 2007; b) comparar a influência destas rodovias na dinâmica do desmatamento; e c) investigar e diferenciar os principais processos que levam a perda da cobertura florestal nesta região.

\section{MATERIAL E MÉTODOS}

\section{Localização da Área de Estudo}

A área de estudo compreende uma subárea da região sul do Estado de Roraima (Figura 1) e engloba quatro municípios: 


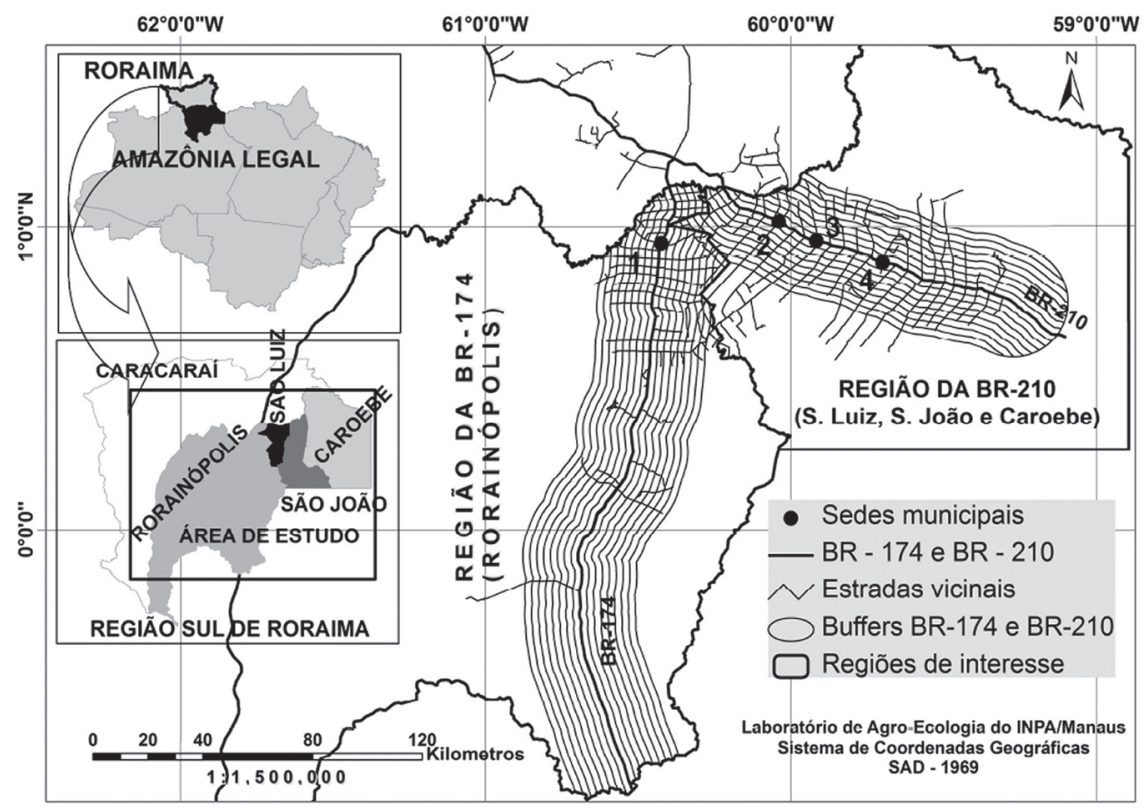

Figura 1 - Localização da área de estudo abrangendo parte da região Sul do Estado de Roraima, formada por quatro municípios: (1) Rorainópolis (região da BR-174), (2) São Luiz do Anauá, (3) São João da Baliza e (4) Caroebe (região da BR-210). A figura mostra também, como parte da metodologia, as faixas de $20.000 \mathrm{~m}$ em ambos os lados das duas rodovias, sendo estas subdivididas por faixas de $2.500 \mathrm{~m}$.

Rorainópolis, cortado pela BR-174 (Manaus - AM/Boa Vista - RR), São Luiz do Anauá, São João da Baliza e Caroebe, cortados pela BR-210 (Perimetral Norte). Excluindo-se, portanto, da região sul, apenas o município de Caracaraí. O recorte totaliza uma área de $51.814 \mathrm{~km}^{2},(52 \%)$ de um total de aproximadamente $99.642,3 \mathrm{~km}^{2}$ da região sul de Roraima.

Em Rorainópolis, com população de 24.466 habitantes em 2007 (Brasil, IBGE 2009), a BR-174 possui uma extensão de $134,2 \mathrm{~km}$, desde a divisa do Estado de Roraima com o Amazonas, dentro da Terra Indígena (TI) Waimiri Atroarí, ao sul, alcançando a divisa com o município de Caracaraí, formada pelo rio Anauá e situada ao norte da área de buffer. A rodovia BR-210 (Perimetral Norte, que foi prevista para ligar o Oceano Atlântico ao Pacífico no âmbito do Programa de Integração Nacional - PIN, nos governos militares), tem uma extensão de 480,9 km dentro do Estado de Roraima. Em sua área de influência, formada por três municípios, a BR-210 possui $115,6 \mathrm{~km}$, iniciando no rio Anauá, que faz a divisa entre o município de São Luiz do Anauá e Caracaraí, até ao rio Jatapú (limite noroeste da T.I. Trombetas-Mapuera), situado no município de Caroebe. Nessa parte da rodovia, o asfalto se estende apenas até São João da Baliza, a $67,5 \mathrm{~km}$ do rio Anauá, restando, portanto, cerca de $50 \mathrm{~km}$ a serem asfaltados até o rio Jatapú. Os três municípios da área de influencia da BR-210 somavam uma população de 18.533 habitantes até 2007 (Brasil, IBGE 2009).

\section{Dados cartográficos e coleta de informações de campo}

Para as análises espaciais, utilizaram-se os dados de desmatamento do período de 2001 a 2007 fornecidos pelo Programa de Monitoramento do Desmatamento - PRODES (Brasil, INPE 2008), em formato vetorial (shapefile), com resoluçáo espacial de 60 metros, da regiāo Sul do Estado de Roraima. Para verificar as informaçóes obtidas dos dados do PRODES foram realizadas análises visuais em 10 cenas TM Landsat 5, órbita/ponto 231/59 e 231/60 (composição colorida R5G4B3) da área de estudo, abrangendo o período analisado e obtido do catálogo de imagens do INPE (http:// www.dgi.inpe.br/CDSR/). Para o georreferenciamento das imagens foi utilizado como base o mosaico de cenas Landsat (geocover) da Zona UTM 21N do ano 2000 fornecido pela National Aeronautics and Space Administration - NASA (https://zulu.ssc.nasa.gov/mrsid). A informação cartográfica dos Projetos de Assentamento da regiáo Sul de Roraima foi obtida pela base de dados do INCRA (2007), e a representação da malha viária pertencente à região Sul de Roraima, foi extraída dos dados do SIVAM/SIPAM (2007), para a Amazônia Legal. Dados cartográficos de Terras Indígenas (TI) e de Unidades de Conservação (UC) da região Sul de Roraima, bem como arquivos vetoriais dos limites municipais, também foram obtidos do SIVAM/SIPAM (2007). Todas as análises foram realizadas no programa computacional ArcGis. 
O termo "PAs", acrônimo para Projetos de Assentamento, foi designado para se referir a todas as modalidades de projetos de assentamentos instituídos pelo INCRA na área de estudo.

\section{Levantamento de campo}

O levantamento de dados de campo foi realizado entre os dias 30 de Novembro e 16 de Dezembro de 2007. Este consistiu de visitas a órgãos governamentais sediados em Boa Vista e também no sul do Estado. Em Boa Vista foram visitados os principais órgãos governamentais do Estado e do Governo Federal ligados a questôes ambientais e de fiscalização e entidades da sociedade civil organizada. Nas visitas foram ouvidas exposiçôes dos entrevistados referentes à atuação de cada órgão em relaçáo ao sul do Estado, para melhor compreensão dos arranjos institucionais na regiáo.

Ainda no sul, nos cinco municípios que formam a região, também foram obtidas informaçôes por meio de entrevistas junto aos pequenos agricultores, proprietários de lotes de assentamentos, madeireiros, dirigentes de associaçóes rurais e de cooperativas, posseiros e grileiros de terras. As entrevistas, tanto na capital como no sul, tiveram caráter informal. Para a realização das entrevistas foram percorridos, de automóvel e motocicleta, cerca de 2500 quilômetros, entre rodovias, carreadores e estradas vicinais da regiáo.

\section{Metodologia}

Em ambiente de Sistemas de Informaçóes Geográficas SIG, do programa computacional ArcGis 9.1, foram criados dois buffers de $20 \mathrm{~km}$ de largura de faixa ao redor das principais rodovias da área de estudo, um para a rodovia BR-174 e outro para a rodovia BR-210. Os dois buffers foram então subdivididos em oito faixas de 2.500 metros no sentido do seu comprimento. O primeiro buffer, denominado "Regiáo da BR174 ", foi restrito ao município de Rorainópolis e o segundo, denominado "Região da BR-210" foi restrito aos municípios de São Luiz do Anauá, São João da Baliza e Caroebe (Figura 1).

A informação da rede viária de estradas (SIVAM/SIPAM 2007) da área de estudo foi atualizada a partir da edição manual (vetorização) derivada de imagens Landsat TM, resolução espacial de 30 metros, para o ano de 2007. A seguir foram quantificadas as áreas totais (ha) de desmatamento e o comprimento de estradas $(\mathrm{km})$ presentes em cada sub-região e em cada faixa de $2500 \mathrm{~m}$. Verificou-se, também, as ocorrências de desmatamento no interior do buffer de $20 \mathrm{~km}$ e suas faixas de distância, assim como em áreas de PAs, pertencentes a cada sub-região. Para essa verificação os arquivos vetoriais, tanto de desmatamento quanto dos PAs e das faixas de distância, foram convertidos para arquivos matriciais (raster) e, posteriormente submetidos a operaçôes de álgebra de mapa entre eles.

Para se determinar as dimensóes dos polígonos de desmatamento e, indiretamente, determinar seus prováveis agentes causadores nas duas regiôes no período analisado, utilizaram-se de análises visuais a partir das informaçóes contidas nas representaçóes vetoriais (polígonos) de desmatamento do PRODES (Brasil, INPE 2008) sobrepostas às imagens TM Landsat 5 (composição $R(5) \mathrm{G}(4) \mathrm{B}(3)$ ). Primeiramente, as informaçóes de desmatamento do PRODES, agrupadas de 2001 a 2007, foram desmembradas para desmatamento ano a ano, em sete layers temáticos, separados para cada região. Em seguida, a partir de análise visual sobre os layers, os polígonos de desmatamento $<6,25$ ha (área mínima detectada pela metodologia do PRODES) adjacentes a outros polígonos maiores ou que a soma das áreas serem $>6,25$ ha, foram incorporados a estes, presumindo que fazem parte de uma mesma área desmatada. Já os polígonos < 6,25 ha que se apresentavam "isolados" foram excluídos das análises, considerados como "ruídos". Os polígonos $<6,25$ ha, provavelmente, seriam gerados a partir da intersecção de várias grades sobrepostas aos desmatamentos (e.ex. grade "guia" das imagens TM Landsat e grade de linhas regulares de $\sim 0,25^{\circ}$ ) observados nos arquivos de dados do INPE e disponibilizado aos usuários do sistema PRODES (Dalton M. Valeriano, com. pess.).

Houve também a necessidade de se diferenciar os polígonos, para saber qual era, de fato, polígono de desmatamento causado por um "único" ator, daqueles considerados como "artefatos" ou "espúrios". Grandes polígonos de desmatamento tinham o formato regular (Cochrane 2000; Alencar et al. 2004), e.g. um retângulo, e se ajustavam quase perfeitamente ao desmatamento observado nas imagens TM Landsat. Estes foram causados, provavelmente, por grandes proprietários de terras. Já os artefatos, em nossa área de estudo, seriam grandes polígonos de desmatamento, com formato muito irregular, abrangendo, muitas vezes, quase todo desmatamento de uma estrada vicinal. Estes seriam resultados da reunião de vários polígonos menores, desmatados, provavelmente, por diferentes atores e em datas diferentes entre si, mas que foram agrupados, em um só ano, posterior aos eventos, de acordo com a metodologia do PRODES (Câmara et al. 2006). Esse fato decorre devido, provavelmente, à nossa área de estudo passar grande parte do ano encoberta por nuvens, dificultando a deteç̧áo do desmatamento pelo sistema PRODES anualmente. Dessa forma, os polígonos considerados artefatos, também foram excluídos das análises. Ao todo foram excluídos 7.206 ha $(26,9 \%)$ de desmatamento na área de influência da BR-174 e 5.880,3 ha (9,8\%) na área de influência da BR-210 no período analisado. Os polígonos de desmatamento considerados válidos para análise foram divididos em três classes de tamanho em hectares (ha): 6,25 $\leq X<18,75$ ha (pequenos agricultores rurais), $18,75 \leq X<$ 31,25 ha (médios proprietários rurais) e $X \geq 31,25$ ha (grandes proprietários rurais). 


\section{RESULTADOS E DISCUSSÃO}

\section{Análise da ocorrência de desmatamento vs. Estradas vicinais, faixas de distância e PAs}

A extensão total das estradas vicinais da regiâo da BR174 foi de $1.014 \mathrm{~km}$, com $971 \mathrm{~km}(95,8 \%)$ abarcados pelo buffer. Na regiấo da BR-210 contabilizou-se uma extensão de $1.088 \mathrm{~km}$ de estradas vicinais, das quais $84,7 \%(922 \mathrm{~km})$ do total encontravam-se no interior da área de buffer (Tabela 1). Considerando-se as estradas localizadas no interior das áreas de PAs da regiáo da BR-210, estas totalizaram uma extensão de $699 \mathrm{~km}$. Nos PAs da regiáo da BR-174 encontrou-se um total de $867 \mathrm{~km}$ de estradas vicinais.

O desmatamento total acumulado para o buffer da região de Rorainópolis (BR-174) foi de 24.257 ha. O desmatamento no buffer representou $88,9 \%$ de desmatamento ocorrido no município de Rorainópolis no período entre 2001 e 2007 (Tabela 2). Para o buffer da BR-210 a área total de desmatamento somou 44.787 ha. Essa área desmatada representou $75,2 \%$ do desmatamento ocorrido na área de influência da BR-210 no período.

A distribuição de desmatamento verificada no buffer da BR-174, diminuindo a partir das faixas mais próximas para as faixas mais distantes da estrada, corrobora com a maioria dos estudos sobre a dinâmica de desmatamento na Amazônia (p.ex.: Soares-Filho et al. 2001; 2002; 2004; e 2006; Nepstad et al. 2001; Geist e Lambin 2002; Lambin et al. 2003; Asner et al. 2006; Ewers e Laurance 2006; Fearnside et al. 2009), tanto no período analisado (2001-2007) quanto no acumulado até 2007. Surpreendentemente, na região da BR-210, no período

Tabela 1 - Estradas vicinais (km) nas áreas de influência das BR-210 e BR174, no Sul de Roraima.

\begin{tabular}{cccccc}
\hline Estradas Vicinais $(\mathrm{km})$ & BR-210 & $\%$ & BR-174 & $\%$ & Total \\
\hline Vicinais (sem BRs) & 1.088 & 100,0 & 1.014 & 100,0 & 2.102 \\
Vicinais dentro buffers & 922 & 84,7 & 971 & 95,8 & 1.893 \\
Vicinais nos PAs & 699 & 64,3 & 867 & 85,6 & 1.566 \\
Vicinais nos PAs buffers & 563 & 51,7 & 820 & 80,9 & 1.383 \\
\hline
\end{tabular}

Tabela 2 - Extensão das áreas de influência das BR-210 e BR-174 e desmatamento acumulado (ha) por período analisado.

\begin{tabular}{cccccc}
\hline Área (ha) & BR-210 & $\%$ & BR-174 & $\%$ & Total \\
\hline Região de influência & 1.796 .400 & 100,0 & 3.385 .000 & 100,0 & 5.181 .400 \\
$\begin{array}{c}\text { Desmatamento até } \\
\text { 2007 }\end{array}$ & 184.900 & 10,3 & 101.760 & 3,0 & 286.660 \\
$\begin{array}{c}\text { Desmatamento } \\
\text { 2001 a 2007 }\end{array}$ & 59.570 & 32,2 & 26.670 & 26,2 & 86.240 \\
$\begin{array}{c}\text { Desmatamento } \\
\text { buffer (01-07) }\end{array}$ & 44.787 & 75,2 & 24.257 & 90,9 & 69.044 \\
\hline
\end{tabular}

analisado (2001-2007), não foi observado esse efeito. No buffer da BR-210 a maior área acumulada de desmatamento ocorreu na faixa entre $12.500 \mathrm{~m}$ e $15.000 \mathrm{~m}$ (sexta faixa), com total acumulado no período de 6.570 ha contra 6.310 ha da segunda faixa de distância (Tabela 3). Esse fato pode ser explicado, em parte, devido à abertura de lotes do PA São Luizão e a grandes desmatamentos em fazendas para a formação de pastagens, localizadas naquela faixa de distância da estrada principal (Figura 1). O fato de que grande parte do desmatamento próximo às estradas principais já terem sido realizados antes de 2001 também pode ter contribuído para esse resultado. A correlação inversa entre maior área desmatada e menor distância da estrada se verifica quando é considerado o desmatamento total acumulado para a regiáo até o ano de 2007 (Figura 2b).

O desmatamento acumulado até 2007 e o ocorrido entre 2001 e 2007 nos PAs do Sul de Roraima, estáo fortemente correlacionados com a ocorrência de estradas vicinais dentro deles (Figura 2a) e com o número de famílias assentadas (Laurance et al. 2002; Soares-Filho et al. 2004, 2006). Os PAs das duas regiôes foram responsáveis por $67,4 \%$ (58.086 ha)

Tabela 3 - Áreas das faixas de buffer, desmatamento acumulado em ha de 2001 a 2007 (Desmat_01/07) e até 2007 (Desmat_até07), percentuais (\%) de desmatamento acumulado entre 2001 a 2007 e até 2007 e ocorrências de estradas vicinais $(\mathrm{km})$ dentro das faixas de distância da rodovia BR-210 e da rodovia BR-174.

\begin{tabular}{|c|c|c|c|c|c|c|c|}
\hline & Faixas & Área & Desmat_ & $1 / 07$ & Desmt_a & é07 & Estradas \\
\hline & Metros & Hectares & Hectares & $\%$ & Hectares & $\%$ & $\mathrm{~km}$ \\
\hline & 2.500 & 68.820 & 5.168 & 7,5 & 34.222 & 50 & 119,2 \\
\hline & 5.000 & 67.880 & 6.464 & 9,5 & 25.415 & 37 & 124,5 \\
\hline & 7.500 & 65.970 & 5.388 & 8 & 21.975 & 33 & 118,2 \\
\hline & 10.000 & 63.470 & 5.864 & 9 & 20.134 & 32 & 121,0 \\
\hline & 12.500 & 61.800 & 5.879 & 9,5 & 16.500 & 27 & 111,5 \\
\hline & 15.000 & 60.360 & 6.634 & 11 & 13.690 & 23 & 99,6 \\
\hline & 17.500 & 57.810 & 5.751 & 10 & 10.280 & 18 & 101,0 \\
\hline & 20.000 & 51.950 & 3.638 & 7 & 6.890 & 13 & 49,1 \\
\hline & Total & 498.060 & 44.787 & 9 & 149.106 & 30 & 844,1 \\
\hline & 2.500 & 116.600 & 3.178 & 3 & 35.926 & 31 & 111,4 \\
\hline & 5.000 & 114.200 & 4.115 & 3,6 & 14.397 & 13 & 103,0 \\
\hline & 7.500 & 112.100 & 3.275 & 3 & 12.050 & 11 & 94,2 \\
\hline & 10.000 & 111.000 & 3.834 & 3,5 & 10.540 & 9 & 100,4 \\
\hline & 12.500 & 107.900 & 3.150 & 3 & 8.571 & 8 & 86,1 \\
\hline & 15.000 & 104.800 & 2.578 & 2,5 & 5.233 & 5 & 67,8 \\
\hline & 17.500 & 102.700 & 2.389 & 2 & 4.292 & 4 & 59,3 \\
\hline & 20.000 & 99.580 & 1.738 & 2 & 2.866 & 3 & 45,3 \\
\hline & Total & 868.880 & 24.257 & 3 & 93.875 & 11 & 667,5 \\
\hline
\end{tabular}




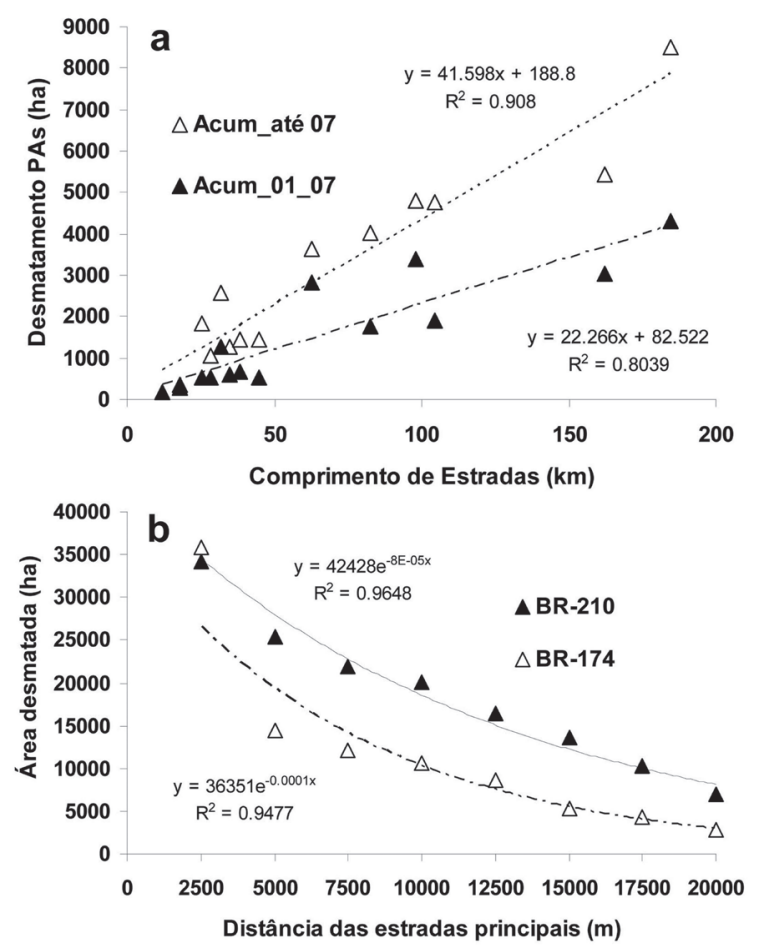

Figura 2 - (a) Relação entre área desmatada (ha) e comprimento de estradas vicinais $(\mathrm{km})$ dentro de projetos de assentamento e (b) relação entre área desmatada acumulada (ha) dentro de cada faixa e sua respectiva distância (m) das BR-174 e BR-210. Na análise em (a) considerou-se o desmatamento acumulado até 2007 (Acum_até 2007) e 0 acumulado de 2001 a 2007 (Acum 01 07). Para a análise em (b) foi considerado o desmatamento acumulado até 2007 em ambas as rodovias. do total desmatado (86.240 ha) entre 2001 a 2007 naquelas áreas (Tabelas 4 e 5). Sendo que os PAs foram responsáveis por $86,9 \%$ dos desmatamentos ocorridos na área de influência da BR-174 contra 58,6\% dos desmatamentos ocorridos na regiáo de influência da BR-210 no período.

De modo geral, o desmatamento per capta foi 2,1 vezes maior nos PAs da regiáo da BR-210 do que nos PAs da regiáo da BR-174 entre 2001 e 2007. Isto é semelhante ao resultado encontrado considerando-se apenas o desmatamento ocorrido nos buffers das duas sub-regiôes, onde o desmatamento encontrado foi cerca de 2 vezes maior no buffer da BR-210.

\section{Dinâmica de mudanças de cobertura da terra no Sul do Estado de Roraima}

Dentro dos PAs da Regiáo sul de Roraima acontece a criação de novas fazendas por um mecanismo de concentração de terras. Fazendeiros ou pequenos e médios proprietários de terra da própria região ou vindos de outros lugares, principalmente de Rondônia, compram um, dois ou mais lotes de terras numa estrada vicinal qualquer (Fearnside 2008) com o objetivo principal de criar gado (Caviglia-Harris 2005). Com o passar dos anos estes fazendeiros váo comprando mais lotes vizinhos, aumentando, assim, sua área total. Esse processo está bastante consolidado em faixas de distância da estrada principal que chegam até cerca de $20 \mathrm{~km}$ ou mais em determinadas estradas vicinais. $\mathrm{O}$ padrão de desmatamento acumulado resultante, via de regra, obedece a um padrão de "contágio" (Figura 3), semelhante a ondas de difusão (SoaresFilho et al. 2004).

Tabela 4 - Projetos de Assentamento (PAs) da região da BR-174, em Rorainópolis.

\begin{tabular}{lccccccc}
\hline \multirow{2}{*}{ PAs } & Área & \multicolumn{2}{c}{ Área Desmat. Acum. } & \multicolumn{2}{c}{ Área Desmat. 01 a 07 } & Famílias Assentadas & Desmate/ Fam.(ha ${ }^{-1}$ ). ano ${ }^{-1}(01-07)$ \\
\cline { 2 - 8 } & ha & ha & $\%$ & ha & $\%$ & Unitário & Relação \\
\hline PA INTEGRAÇÃO & 11.200 & 4.100 & 36,8 & 2.134 & 52 & - & - \\
PA EQUADOR & 16.900 & 1.500 & 8,6 & 800 & 53,3 & 231 & 0,5 \\
PA JUNDIÁ & 13.400 & 1.400 & 10,7 & 528,5 & 37,8 & 153 & 0,7 \\
PA LADEIRÃO & 21.400 & 1.100 & 5,0 & 523,4 & 47,6 & 182 & 0,6 \\
PAD ANAUÁ & 221.800 & 68.400 & 35,0 & 19.200 & 28,0 & 2.943 & 1,0 \\
\hline Total & 284.700 & 76.500 & 26,9 & 23.186 & 29,2 & 3.509 & 0,9 \\
\hline
\end{tabular}

Tabela 5 - Projetos de Assentamento (PAs) da região da BR-210.

\begin{tabular}{|c|c|c|c|c|c|c|c|}
\hline \multirow{2}{*}{ PAs } & \multirow{2}{*}{$\begin{array}{c}\text { Área } \\
\text { ha }\end{array}$} & \multicolumn{2}{|c|}{ Área Desmat. Acum. } & \multicolumn{2}{|c|}{ Área Desmat. 01 a 07} & \multirow{2}{*}{$\begin{array}{c}\text { Famílias Assentadas } \\
\text { Unitário }\end{array}$} & \multirow{2}{*}{$\begin{array}{c}\text { Desmate/ Fam.(ha-1). ano-1 (01-07) } \\
\text { Relação }\end{array}$} \\
\hline & & ha & $\%$ & ha & $\%$ & & \\
\hline PA BOM-SUCESSO & 16.400 & 5.100 & 31,1 & 3.100 & 60,8 & 197 & 2,3 \\
\hline PA INTEGRAÇÃO & 26.700 & 4.100 & 15,5 & 4.100 & 100,0 & 332 & 1,8 \\
\hline PA JATAPÚ & 164.300 & 62.200 & 37,8 & 24.700 & 39,7 & 1.882 & 1,9 \\
\hline PA SÃO LUIZÃO & 10.600 & 6.200 & 58,1 & 2.800 & 45,2 & 183 & 2,2 \\
\hline PA SERRA TALHADA & 3.300 & 200 & 5,5 & 200 & 100,0 & 32 & 0,8 \\
\hline Total & 221.300 & 77.800 & 35,2 & 34.900 & 44,9 & 2.626 & 1,9 \\
\hline
\end{tabular}




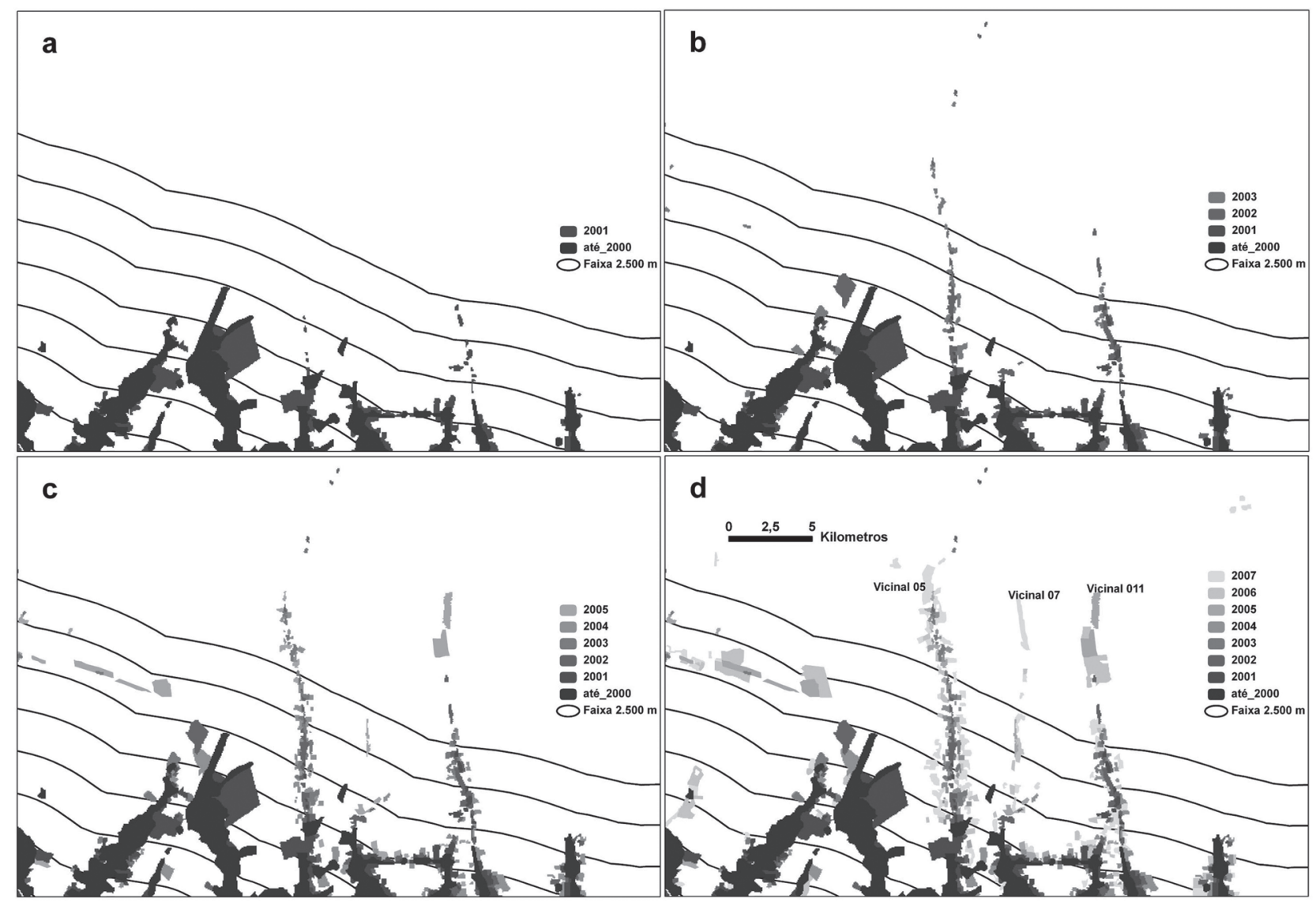

Figura 3 - Seqüência de imagens de desmatamento do PRODES mostrando padrões de "contágio" evoluindo através dos anos e ao longo das vicinais 05,07 e 011 do PA Jatapú, em Caroebe, região da BR-210. Em (a) (anos 2000 e 2001), 0 desmatamento ainda se encontra restrito às faixas de buffer e dentro da área do PA Jatapú. Em (b) (anos 2002 e 2003) já se nota a extrapolação do desmatamento da linha divisória do buffer de 20.000 metros. Em (c) (anos 2004 e 2005) e em (d) (anos 2006 e 2007) há a incorporação de mais polígonos de desmatamento aos já previamente existentes, dentro e fora dos limites do buffer e do PA.

Ao nível de propriedade, os padróes observados foram recorrentes para todas as vicinais visitadas, tanto na região da BR-210 como na regiáo de Rorainópolis (BR-174). Ou seja, pastagens predominam nos dois primeiros terços das vicinais e atividades mais diversificadas, tais como plantios de banana e culturas anuais, além de pastagens, se concentram no último terço. A Figura 4 mostra uma imagem TM Landsat $5 \mathrm{R}(5)$; $\mathrm{G}(4)$; $B(3)$ de agosto de 2009 registrando algumas clareiras de desmatamento seguindo o padrão descrito por relatos de moradores da regiáo da BR-210. De acordo com esses relatos, grileiros estariam demarcando lotes de 60 ha para pequenos agricultores e áreas de 500 ha para grandes proprietários em um "travessão imaginário" seguindo em paralelo com a Terra Indígena Wai-Wai, partindo do final da vicinal 07 do PA Jatapú, em Caroebe.

\section{Exploração madeireira}

Em Rorainópolis, atual pólo madeireiro do sul do estado, madeireiros transportam toras para as serrarias à noite para

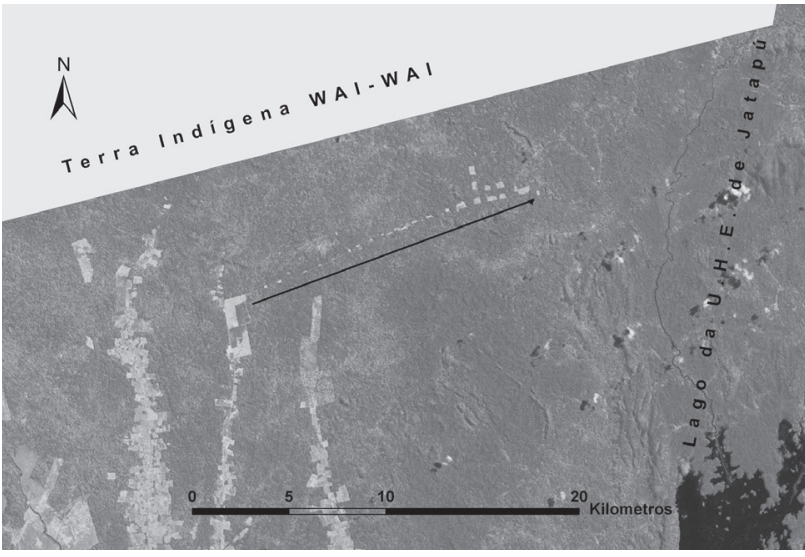

Figura 4 - Imagem Landsat TM5, composição colorida original $R(5) G(4) B(3)$ e Órbita Ponto 231/059 (em tons de cinza) de agosto de 2009, mostrando desmatamento recente (indicado pela seta, alinhados à estrada recém-criada) a partir do final da vicinal 07 do PA Jatapú, em Caroebe, região da BR-210. Os polígonos maiores já apareciam nos dados de desmatamento do ano de 2008 do PRODES. 
burlar a fiscalização. Esses madeireiros usariam uma mesma guia do Documento de Origem Florestal - DOF para transportar várias cargas de madeira das áreas em exploração ao pátio das serrarias, apresentando o DOF apenas se a fiscalização os parasse para averiguações. Empresas madeireiras "esquentariam" (regularização de forma fraudulenta) a madeira irregular em seus pátios através de grandes planos de manejos licenciados pelos órgãos ambientais.

O quadro é agravado ainda mais devido à pressão exercida por madeireiros vindos de fora de Roraima para a exploração florestal. Considerando que o período chuvoso em Roraima não coincide com aquele da borda sul da Amazônia, madeireiros de Rondônia, sul do Pará e do Acre vêm todos os anos explorar madeira em Roraima. Esses madeireiros teriam a preferência das grandes indústrias madeireiras na exploração florestal por estarem mais capitalizados. Aos madeireiros locais e a outros pequenos madeireiros independentes, também vindos de fora, restariam apenas a possibilidade de trabalhar com pequenas serrarias e competiriam junto aos agricultores por madeiras legalizadas através de autorizaçóes de corte (documento expedido aos pequenos agricultores rurais para o aproveitamento da madeira que seria cortada nos desmatamentos legalmente autorizados pela FEMACT). Devido a conflitos e ao volume de denúncias a Fundaçáo Estadual de Meio Ambiente Ciência e Tecnologia do Estado de Roraima - FEMACT suspendeu as licenças de corte até segunda ordem. Um fiscal da fundaçáo observou que os pedidos de autorização de corte eram tantos que a FEMACT conseguiria liberar apenas $30 \%$ dos pedidos anualmente.

\section{Distribuição do desmatamento por classe de tamanho de polígono (ha)}

Alguns trabalhos sobre desmatamento na Amazônia utilizaram o tamanho da propriedade onde ocorreu o desmatamento para identificar o agente causador do mesmo (Fearnside 2003; Soares-Filho et al. 2004; Aldrich et al. 2006) e sua trajetória dinâmica (Alves 2002; Soares-Filho $e t$ al. 2004; D'Antona et al. 2006). Neste trabalho utilizou-se o tamanho do polígono de desmatamento do PRODES (Brasil, INPE 2008) como indicador do possível agente causador do desmatamento ocorrido na área de estudo. Assim, cerca de 60\% (11.700 ha) do desmatamento acumulado entre 2001 e 2007 na regiāo da BR-174, considerando apenas os dados ditos "válidos" para a análise, ocorreu na classe entre 6,25 a 18,75 ha (Figura 5). O desmatamento ocorrido nesta classe foi atribuído a pequenos agricultores. A classe intermediária entre 18,75 a 31,25 ha concentrou $17,4 \%(3.402,5$ ha) do desmatamento ocorrido (dados válidos) e foi atribuído a médios proprietários rurais. Do mesmo modo, os polígonos maiores que 31,25 ha corresponderam a $22,7 \%$ (4.436 ha) do desmatamento acumulado no período analisado e foi atribuído a grandes proprietários rurais. Considerando-se a regiáo de influência da BR-210 no mesmo período, a primeira classe de polígonos contribuiu com $43,4 \%$ do desmatamento (23.247,8 ha) ocorrido e foi atribuído a pequenos agricultores. A concentração observada para a classe acima de 31,25 ha totalizou uma área de 21.422 ha (40\%), sendo sua causa atribuída a grandes proprietários rurais. A classe intermediária concentrou 16,6\% (8.913 ha) do desmatamento restante e, semelhantemente ao ocorrido em Rorainópolis (região de influência da BR-174), esse desmatamento foi atribuído a médios proprietários rurais.

O grande desmatamento observado na classe acima de 31,25 ha (40\%) na regiáo da BR-210, bem maior do que o observado na regiấo de Rorainópolis (22,7\%) na mesma classe, pode ser explicado, em parte, devido à forte concentraçáo fundiária observada nos PAs (Mourão 2003) e a grande quantidade de fazendas de gado existentes naquela região. Estes resultados corroboram com estudos de Soares-Filho et al. (2004) e Fearnside (2005) que sugerem que grandes proprietários de terra têm maior potencial para desmatar e o fazem em áreas maiores. O contrário foi observado na regiáo da BR-174 com maior desmatamento relativo (60\%) ocorrendo na classe entre 6,25 e 18,75 ha. Isto pode sugerir que há uma menor concentração fundiária e maior predominância de pequenos proprietários rurais nesta regiấo. Embora o percentual de desmatamento atribuído a pequenos proprietários ser bastante alto na região da BR-210 $(43,4 \%)$ esse percentual pode não refletir o que aconteceria realmente naquela regiáo. Há a possibilidade de que grandes proprietários, com várias posses de terra, possam distribuir o desmatamento entre seus lotes em áreas < do que 31,25 ha. Mourão (2003) relatou que $45 \%$ dos assentados do PA Jatapú em Caroebe, possuíam de 2 a 3 lotes de terras e que $15 \%$ possuíam mais de três lotes. Carreiro e Fearnside (2011), estudando a dinâmica de desmatamento e a expansão de posses em Apuí (Sul do Amazonas), constataram que pelo menos

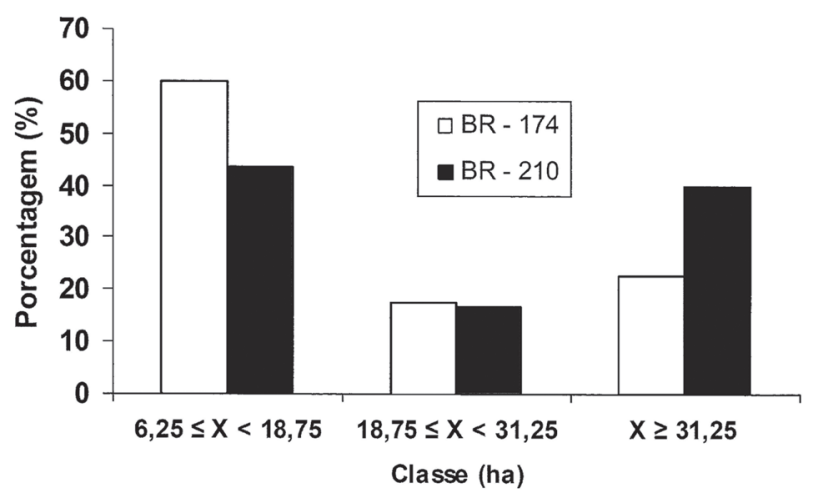

Figura 5 - Distribuição percentual do desmatamento por classe de tamanho de polígono (ha): $6,25 \leq X<18,75$ ha (pequenos agricultores rurais), 18,75 $\leq X<31,25$ ha (médios proprietários rurais) e $X \geq 31,25$ ha (grandes proprietários rurais). 
$40 \%$ dos proprietários entrevistados tinham entre dois a cinco lotes e que cerca de $16 \%$ tinham entre 6 a 10 lotes de terra.

\section{CONCLUSÕES}

As duas regióes apresentaram diferenças substanciais nos processos, na velocidade e nos padróes de distribuição do desmatamento no período analisado, tendo os Projetos de Assentamento, juntamente com estradas vicinais, como os principais vetores de desmatamento. Os PAs foram responsáveis por $67,4 \%$ do desmatamento acumulado considerando a totalidade da área de estudo, sendo que para a regiāo de influência da BR-174 esse valor chegou a 86,9\%.

Grandes proprietários rurais tiveram maior participação no desmatamento na região da BR-210 do que na regiāo da BR-174. O desmatamento ocorrido na regiáo da BR-174 foi causado, predominantemente, por pequenos agricultores rurais. A forte presença de madeireiros vindos de fora da região para a exploração florestal e conseqüente pressão por madeiras licenciadas junto aos pequenos agricultores podem ter influenciado, de maneira indireta, na formaçáo de pequenas áreas desmatadas na regiáo da BR-174.

A exploração madeireira predatória e novas ocupaçóes de terras, tanto por pequenos e grandes proprietários, estáo acontecendo de forma rápida e desordenada. Este quadro indica um forte potencial para a perda de floresta em Roraima caso o fluxo de migração para esta área aumentar, como seria esperado se Roraima for conectada ao Arco do Desmatamento com a reabertura da Rodovia BR-319, ligando Manaus a Porto Velho.

\section{AGRADECIMENTOS}

Agradecemos ao Conselho Nacional de Desenvolvimento Científico e Tecnológico - CNPq por custear as pesquisas e as excursóes de campo (Processo: 557152/2005-4) e à rede GEOMA, ao INPA e à FAPEAM pela bolsa de estudo concedida a P.E.B. Agradecemos também a dois revisores anônimos por suas sugestóes e comentários.

\section{BIBLIOGRAFIA CITADA}

Albuquerque, F.J.B. de; Coelho, J.A. de M.; Vasconcelos, T.C. 2004. As políticas públicas e os projetos de assentamento. Estudos de Psicologia, 9: 81-88.

Aldrich, S.P.; Walker, R.T.; Arima, E.Y.; Caldas, M.M.; Browder, J.O.; Perz, S. 2006. Land-cover and land-use change in the Brazilian Amazon: smallholders, ranchers and frontier stratification. Economic Geography 82: 265-288.

Alencar, A.A.C; Solórzano, L.A.; Nepstad, D.C. 2004. Modeling forest understory fires an eastern Amazonian landscape. Ecological Applications, 14: 139-149.
Alves, D. S. 2002. Space-time dynamics of deforestation in Brazilian Amazonia. International Journal of Remote Sensing, 23: 2903-2908.

Asner, G.P.; Broadbent, E.N.; Oliveira, P.J.C.; Keller, M.; Knapp, D.E.; Silva, J.N.M. 2006. Condition and fate of logged forests in the Brazilian Amazon. Proceedings of the National Academy of Sciences of the United States of America, 103: 12947-12950.

Barbosa, R.I. 1990. Analise do setor madeireiro do Estado de Roraima. Acta Amazonica, 20: 193-209.

Barbosa, R.I.; Pinto, F.S.; Souza, C.C. 2008. Defforestation in Roraima State: historical data and spatio-temporal distribution. Relatório Técnico. Ministério da Ciência e Tecnologia, Instituto Nacional de Pesquisas da Amazônia -INPA, Núcleo de Pesquisas de Roraima, Boa Vista-RR. 10 pp. (In Portuguese)

Barreto, P.; Pinto, A.; Brito, B.; Hayashi, S. 2008a. Who's the owner of the Amazon? Instituto do Homem e Meio Ambiente da Amazônia-IMAZON, Belém-PA, 72 pp.

Brasil, IBGE (Instituto Brasileiro de Geografia e Estatística). 2009. IBGE. Rio de Janeiro-RJ. (www.sidra.ibge.gov.br/). Acesso 10/02/09.

Brasil, INCRA (Instituto Nacional de Colonização e Reforma Agrária). 2007. Diretoria de Obtenção de Terras e Implantação de Projetos de Assentamento - DT. Ministério do Desenvolvimento Agrário - MDA. Brasília-DF.

Brasil, INPE (Instituto Nacional de Pesquisas Espaciais). 2008. Monitoramento da Floresta Amazônica Brasileira por Satélite. INPE, São José dos Campos, São Paulo, SP. ( www.obt.inpe.br/ prodes/). Acesso: 11/05/08.

Brasil, SIVAM/SIPAM. 2007. Banco de Dados IBGE - versão 6 (derivado da recuperaçáo dos dados originais do Projeto RADAMBRASIL). Serviço de Vigilância da Amazônia / Serviço de Proteção da Amazônia, Manaus-AM. (4 CDs).

Câmara, G.; Valeriano, D.M.; Soares, J.V. 2006. Metodologia para o Cálculo da Taxa Anual de Desmatamento na Amazônia Legal. São José dos Campos, INPE, set/2006. <http://www.obt.inpe. br/prodes/metodologia.pdf>. Acesso: 12/09/2010.

Carrero, G.C.; Fearnside. P.M. 2011. Forest clearing dynamics and the expansion of landholdings in Apuí, a deforestation hotspot on Brazil's Transamazon Highway. Ecology and Society 16(2): 26. [online] URL: http://www.ecologyandsociety.org/vol16/ iss $2 / \operatorname{art} 26 /$.

Caviglia-Harris, J.L. 2005. Cattle Accumulation and Land Use Intensification by Households in the Brazilian Amazon. Agricultural and Resource Economics Review, 34: 121-128

Cochrane, M.A. 2000. Forest fire, deforestation and landcover change in the Brazilian Amazon. In: Neuenschwander, L.F.; Ryan, K.C.; Gollberg, G.E.; Greer, J.D. (Eds.). Proceedings from the joint fire Science Conference and Workshop, June 15-17, 1999. "Crossing the millennium: Integrating spatial technologies and ecological principles for a new age in fire management". Vol. 1. Moscow, Idaho: University of Idaho and the International Association of Wildland Fire. 
D’Antona, A.O.; VanWey, L.K.; Hayashi, C.M. 2006. Property size and land cover change in the Brazilian Amazon. Population and Environment, 27: 373-396.

Ewers, R.; Laurance, W.F. 2006. Scale-dependent patterns of deforestation in the Brazilian Amazon. Environmental Conservation, 33: 203-211.

Fearnside, P.M. 1995. Quem desmata a Amazônia os pobres ou os ricos? Ciência Hoje, 19: 113. 26-33.

Fearnside, P.M. 2003. Deforestation control in Mato Grosso: a new model for slowing the loss of Brazil's Amazon forest. Ambio, 32: 343-345.

Fearnside, P.M. 2005. Desmatamento na Amazônia brasileira: história, índices e conseqüências. Megadiversidade, 1: 1-14.

Fearnside, P.M. 2008. The roles and movements of actors in the deforestation of Brazilian Amazonia. Ecology and Society, 13: 23.

Fearnside, P.M.; Graça, P.M.L.A; Keizer, E.W.H.; Maldonado, F.D.; Barbosa, R.I.; Nogueira, E.M.. 2009. Modelagem de desmatamento e emissóes de gases de efeito estufa na região sob influência da Rodovia Manaus-Porto Velho (BR-319). Revista Brasileira de Meteorologia 24: 208-233.

Geist, H.J.; Lambin, E.F. 2002. Proximate causes and underlying driving forces of tropical deforestation. BioScience, 52: 143-150.

Holmes, T.P.; Blate, G.M.; Zweede, J.C.; Pereira, R. Jr.; Barreto, P.; Boltz, F.; Bauch, R. 2002. Financial costs and benefits of reduced-impact logging relative to conventional logging in the eastern Amazon. Forest Ecology and Management, 163: 93-110.

Lambin, E.F.; Geist, H.J.; Lepers, E. 2003. Dynamics of land-use and land-cover change in tropical regions. Environment Resources, 28: 205-241.

Laurance, W.F.; Albernaz, A.K.M.; Schroth, G.;. Fearnside P.M;. Bergen, S.; Ventincinque, E.M.; da Costa, C. 2002. Predictors of Deforestation in the Brazilian Amazon. Journal of Biogeography, 29: 737-748.

Loureiro, V.R.; Pinto, J.N.A. 2005. A questão fundiária na Amazônia. Estudos avançados, 19: 77-98.

Nepstad, D.; Schwartzman, S.; Bamberger, B.; Santilli, M.; Ray, D.; Schlesinger, P.; Lefebvre, P.; Alencar, A.; Prinz, E.; Fiske, G.; Rolla, A. 2006. Inhibition of Amazon Deforestation and Fire by Parks and Indigenous Lands. Conservation Biology, 20: 65-73.
Mourão, G.M.N. 2003. Colonización Reciente Y Asentamientos Rurales En El Sureste De Roraima, Amazonia Brasileña: Entre La Politica Y La Naturaleza. Tese de doutorado, Universidad De Valladolid, Espanha. 480 pp.

Nepstad, D.C.; Carvalho, G.; Barros, A.C.; Alencar, A.; Capobianco, J.P.; Bishop, J.; Moutinho, P.; Lefebvre, P.; Silva Jr., U.L.; Prins, E. 2001. Road paving, fire regime feeedbacks, and the future of Amazon forests. Forest Ecology and Management, 154: 395-407.

Oliveira, A. 2005. BR - 163 Cuiabá-Santarém: Geopolitica, grilagem, violência e mundialização. p. 67-183. In: Torres, M. (Ed.). Amazônia Revelada: Os descaminhos ao longo da BR-163. Conselho Nacional de Apoio a Pesquisa, Brasília-DF.

Rodrigues, A.S.L.; Ewers, R.M.; Parry, L.; Souza Jr., C.; Veríssimo, A.; Balmford, A. 2009. Boom-and-Bust Development Patterns Across the Amazon Deforestation Frontier. Science, 324: 14351437.

Soares-Filho, B.; Assunção, R.M.; Pantuzzo, A.E. 2001. Modeling the spatial transition probabilities of landscape dynamics in an Amazonian colonization frontier. BioScience, 51: 1059-1068.

Soares-Filho, B.; Alencar, A.; Nepstad, D.; Cerqueira, G.; Diaz, M. del C.V.D.; Rivero, S.; Solorzanos, L.; Voll, E. 2004. Simulating the response of land-cover changes to road paving and governance along a major Amazon highway: the Santarém-Cuiaba' corridor. Global Change Biology, 10: 745-764.

Soares-Filho, B.S.; Nepstad, D.C.; Curran, L.; Cerqueira, G.C.; Garcia, R.A.; Ramos, C.A.; Voll, E.; Mcdonald, A.; Lefebvre, P.; Schlesinger, P. 2006. Modelling conservation in the Amazon basin. Nature, 440: 520-523.

Recebido em 24/01/2011

Aceito em 26/05/2011 